\title{
An expert system for process planning of sheet metal parts produced on compound die for use in stamping industries
}

\author{
SACHIN SALUNKHE ${ }^{1}$, DEEPAK PANGHAL ${ }^{1}$, SHAILENDRA KUMAR $^{1, *}$ \\ and $\mathrm{H}$ M A HUSSEIN ${ }^{2,3}$ \\ ${ }^{1}$ Department of Mechanical Engineering, S. V. National Institute of Technology, Surat 395007, India \\ ${ }^{2}$ Advanced Manufacturing Institute, King Saud University, Riyadh 11421, Saudi Arabia \\ ${ }^{3}$ Department of Mechanical Engineering, Faculty of Engineering, Helwan University, Cairo, Egypt \\ e-mail: skbudhwar@med.svnit.ac.in
}

MS received 28 February 2014; revised 28 January 2016; accepted 6 March 2016

\begin{abstract}
Process planning of sheet metal part is an important activity in the design of compound die. Traditional methods of carrying out this task are manual, tedious, time-consuming, error-prone and experiencebased. This paper describes the research work involved in the development of an expert system for process planning of sheet metal parts produced on compound die. The proposed system is organized in six modules. For development of system modules, domain knowledge acquired from various sources of knowledge acquisition is refined and then framed in form of 'IF-Then' variety of production rules. System modules are coded in AutoLISP language and user interface is created using visual basic (VB). The system is capable to automate various activities of process planning including blank modeling, blank nesting, determining punch force required, selection of clearance between punch and die, identifying sheet metal operations, and determining proper sequence of operations for manufacturing the part. The proposed system can be implemented on a PC having VB and AutoCAD software, therefore its low cost of implementation makes it affordable even for small scale sheet metal industries.
\end{abstract}

Keywords. Expert system; process planning; sheet metal parts; compound die; stamping industries; AutoCAD.

\section{Introduction}

Compound die is widely used in sheet metal industries for manufacturing of pierced blanks with good accuracy. Process planning of sheet metal parts is an important activity for the design of a compound die. An experienced die designer or process planner needs to perform various activities for process planning such as blank modeling, blank nesting, determining punch force required, selection of clearance between punch and die, identifying sheet metal operations, and determining proper sequence of operations for manufacturing the part. Traditional methods of carrying out these activities are tedious, time-consuming, skill-intensive, error-prone and largely based on the rich experience-based knowledge of domain experts [1]. A die designer needs to spend many hours consulting hand books, going through empirical formulae, perusing tabulated and graphical information, and making calculations before arriving at practical designs [2]. Further, nowadays sheet metal industries are also facing problems due to scarcity of

*For correspondence experienced die designers and their frequent mobility. Some researchers have applied efforts to develop computer aided systems for process planning of sheet metal parts. For example, Xiao et al [3] developed an expert system using a set of production rules and frames for process planning of axisymmetric deep drawing parts. The system is suited to the process planning of general drawing process and to the strip layout of progressive drawing of axisymmetric parts. Hoffmann et al [4] developed a bending-sequence generator using expert system approach to computerize the process-planning of sheet-metal parts. But planner's interaction is still required. Fang and Tolouei-Rad [5] proposed a rule based expert system for process planning of complex circular shells produced by deep-drawing process. Jin et al [6] developed a knowledge based system (KBS) for design of tube bending processes, including bending methods selection, tool/die design, and process parameters setup. Kang and Park [7] proposed a computer-aided process planning (CAPP) system for rotationally symmetric deep drawing products. Shi et al [8] developed a knowledge-based process planning system to support auto panel die development and design automation. A computerized 
retrieval system for sheet metal parts was proposed by Hussein and Kumar [9]. Tsai et al [10] developed a process planning and die design system for automotive panel production using knowledge-based engineering (KBE) methodology. Potocnik et al $[11,12]$ developed an intelligent system for automatic calculations of stamping process parameters for design of stamping die for manufacturing of circular cup with flange. Further they also reported to develop a KBS for supporting the design of a press plate. Naranje and Kumar [13] proposed a KBS for strip layout design for progressive deep drawing dies. The proposed system is production rule based and consists of eight modules.

From the review of available literature it can be concluded that the worldwide researchers have applied efforts to develop computer aided systems for process planning of sheet metal parts of single operation dies, progressive dies and deep drawing dies. No system has been reported in the literature which is specifically developed for process planning of sheet metal parts produced on compound die. As it is a tedious, time-consuming and experience-based activity, there is stern need to develop an expert system for this task. In the present work, research efforts are applied to develop an expert system for process planning of sheet metal parts produced on compound die for use in stamping industries.

\section{Guidelines for process planning of sheet metal parts produced on compound die}

From the critical review of published literature and detailed discussions with experienced die designers, some basic guidelines for process planning of sheet metal parts produced on compound die are identified [1, 9, 10, 14-18]. A sample of these basic guidelines is given below.

1. The die land and die angle in a compound die depend on sheet thickness. For sheet thickness up to $1.5 \mathrm{~mm}$, the die-land is generally set as $3.5 \mathrm{~mm}$ and die-angle is taken as $1 / 4$ degree.

2. For sheet thickness from 1.6 to $4.5 \mathrm{~mm}$, the die-land is generally set as $4 \mathrm{~mm}$ and die-angle is taken as $1 / 2$ degree.

3. For sheet thickness more than $4.5 \mathrm{~mm}$, the die-land is generally set as $5.5 \mathrm{~mm}$ and die-angle is taken as $3 / 4$ degree.

4. Diameter of piercing punches should not be smaller than the thickness of strip which is to be pierced.

5. If diameter of piercing punch is smaller than thickness of the strip, diameter of punch shank should be at least twice the hole size and cutting face should be ground to the hole size for a distance about twice the stock thickness.

6. The height of the channel should be two times the stock thickness whereas width must be equal to the summation of strip width and clearance.
7. Enough clearance should be provided on the punch for its easy removal; but clearance should be less than 1.5 times of the thickness of strip.

8. The length of punch should be 10 times of the diameter of punch.

9. The gap between the punch and stripper should be at least $0.0075 \mathrm{~mm}$ on each side.

10. For aluminum sheet material of thickness up to $1.0 \mathrm{~mm}$ having shear strength $55.2 \mathrm{~N} / \mathrm{mm}^{2}$, cutting clearance per side must be $2.5 \%$ of sheet thickness for round contours and $3.5 \%$ of sheet thickness for other contours.

11. For stainless steel sheet material of thickness up to $1.0 \mathrm{~mm}$ having shear strength $620 \mathrm{~N} / \mathrm{mm}^{2}$, cutting clearance per side must be $5.2 \%$ of sheet thickness for round contours and $6.4 \%$ of sheet thickness for other contours.

12. For copper sheet material of thickness between 1.0 and $2.0 \mathrm{~mm}$ having shear strength $193 \mathrm{~N} / \mathrm{mm}^{2}$, cutting clearance per side must be $3.3 \%$ of sheet thickness for round contours and $4.0 \%$ of sheet thickness for other contours.

13. If piercing and blanking operations are to be performed on sheet metal part, then generally upper punch is taken as piercing and lower punch as blanking on compound die.

14. If notching and blanking operations are to be performed on sheet metal part, then generally upper punch is taken as notching and lower punch as blanking on compound die.

15. If parting and shaving operations are to be performed on sheet metal part, then generally upper punch is taken as shaving and lower punch as parting on compound die.

Keeping in view of the above basic guidelines and after having detailed discussion with experienced die designers, an expert system labeled as PPCD (process planning for compound die) is developed for process planning of sheet metal parts produced on compound die.

\section{Development procedure of the system PPCD}

Development procedure of the proposed expert system namely PPCD includes knowledge acquisition, framing of production rules of 'IF-Then' variety, verification of production rules from domain experts, sequencing of production rules, identification of suitable computer language for coding of production rules, construction of knowledge base, selection of search strategy, and preparation of graphical user interface (GUI) [2]. Technical knowledge for the development of proposed system is acquired from various sources of knowledge acquisition such as die design handbooks, technical reports, industrial brochures, research papers and through consultation with industrial experts. The acquired knowledge is refined and then framed in form of production rules of 'IF-Then' variety. The system overall 
Table 1. A sample of production rules incorporated in the proposed system.

S.

no.

$1 \quad$ Sheet thickness in $\mathrm{mm} \leq 1.6$

2

Sheet thickness in $\mathrm{mm}>1.6$; and Sheet thickness in $\mathrm{mm} \leq 4.5$

3

Sheet thickness in $\mathrm{mm}>4.5$

4

Sheet material $=$ Tin; and Shear strength $=30-40 \mathrm{~N} / \mathrm{mm}^{2}$; and Sheet thickness in $\mathrm{mm} \leq 1.0$; and Hardness of sheet material $=40-50 \mathrm{HRC}$

5

Sheet material $=$ Stainless steel [AISI 1090]; and Shear strength $=600-650 \mathrm{~N} / \mathrm{mm}^{2}$; and Sheet thickness in $\mathrm{mm} \leq 1.0$; and Hardness of sheet material $=50-55 \mathrm{HRC}$

$6 \quad$ Sheet material $=$ Stainless steel [AISI 1090]; and Shear strength $=600-650 \mathrm{~N} / \mathrm{mm}^{2}$; and Sheet thickness in $\mathrm{mm}>3.0$; and Sheet thickness in $\mathrm{mm} \leq 4.0$; and Hardness of sheet material $=50-55 \mathrm{HRC}$

7 Sheet material $=$ Brass; and Shear strength $=350-400 \mathrm{~N} / \mathrm{mm}^{2}$; and Sheet thickness in $\mathrm{mm} \leq 1.0$; and Hardness of sheet material $=40-50 \mathrm{HRC}$

8

Sheet material $=$ Brass; and Shear strength $=350-400 \mathrm{~N} / \mathrm{mm}^{2}$; and Sheet thickness in $\mathrm{mm}>3.0$; and Sheet thickness in $\mathrm{mm} \leq 4.0$; and Hardness of sheet material $=40-50$ HRC

9 Sheet material $=$ Bronze; and Shear strength $=270-320 \mathrm{~N} / \mathrm{mm}^{2}$; and Sheet thickness in $\mathrm{mm} \leq 1.0$; and Hardness of sheet material $=40-50 \mathrm{HRC}$

10 Sheet material = Bronze; and Shear strength $=270-320 \mathrm{~N} / \mathrm{mm}^{2}$; and Sheet thickness in $\mathrm{mm}>1.0$; and Sheet thickness in $\mathrm{mm} \leq 2.0$; and Hardness of sheet material $=40-50$ HRC

11 Sheet material $=$ Copper; and Shear strength $=180-200 \mathrm{~N} / \mathrm{mm}^{2}$; and Sheet thickness in $\mathrm{mm}>2.0$; and Sheet thickness in $\mathrm{mm} \leq 3.0$; and Hardness of sheet material $=30-35$ HRC

12 Sheet material $=$ Zinc; and Shear strength $=100-150 \mathrm{~N} / \mathrm{mm}^{2}$; and Sheet thickness in $\mathrm{mm} \leq 1.0$; and Hardness of sheet material $=20-25 \mathrm{HRC}$

13 Sheet material $=$ Zinc; and Shear strength $=100-150 \mathrm{~N} / \mathrm{mm}^{2}$; and Sheet thickness in $\mathrm{mm}>1.0$; and Sheet thickness in $\mathrm{mm} \leq 2.0$; and Hardness of sheet material $=20-25$ HRC

14 Sheet material $=$ Aluminum; and Shear strength $=50-60 \mathrm{~N} / \mathrm{mm}^{2}$; and Sheet thickness in $\mathrm{mm} \leq 1.0$; and Hardness of sheet material $=10-20 \mathrm{HRC}$

15 Sheet material $=$ Aluminum; and Shear strength $=50-60 \mathrm{~N} / \mathrm{mm}^{2}$; and Sheet thickness in $\mathrm{mm}>1.0$; and Sheet thickness in $\mathrm{mm} \leq 2.0$; and Hardness of sheet material $=10-20$ $\mathrm{HRC}$

16 Minimum tolerance required on part in $\mathrm{mm} \geq 0.001$; and Maximum tolerance required on part in $\mathrm{mm} \leq 0.02$; and Design feature $=$ hole or slot or oval hole or internal contour cut

Minimum tolerance required on part in $\mathrm{mm} \geq 0.001$; and Maximum tolerance required on part in $\mathrm{mm} \leq 0.02$; and Design feature = external precision contour

18 Minimum tolerance required on part in $\mathrm{mm} \geq 0.001$; and Maximum tolerance required on part in $\mathrm{mm} \leq 0.02$; and Design feature = external boundary cut or notch or side cut

19 Minimum tolerance required on part in $\mathrm{mm} \geq 0.001$; and Maximum tolerance required on part in $\mathrm{mm} \leq 0.02$; and Design feature $=$ close tolerance or finishing or shaving

20 Minimum tolerance required on part in $\mathrm{mm} \geq 0.001$; and Maximum tolerance required on part in $\mathrm{mm} \leq 0.02$; and Design feature $=$ rectangular hole

21 Minimum tolerance required on part in $\mathrm{mm} \geq 0.001$; and Maximum tolerance required on part in $\mathrm{mm} \leq 0.02$; and Design feature $=$ series or pattern of holes with close tolerance

22 Minimum tolerance required on part in $\mathrm{mm} \geq 0.001$; and Maximum tolerance required on part in $\mathrm{mm} \leq 0.02$; and Design feature $=$ to cut of blank or separating part from sheet or removal of pieces or two side external cut on edge
Required operations $=$ piercing and blanking
THEN

Set die-angle $=0.25$ degree; and Die-

land $=3.5 \mathrm{~mm}$

Set die-angle $=0.5$ degree; and Dieland $=4.0 \mathrm{~mm}$

Set die-angle $=0.75$ degree; and Dieland $=5.5 \mathrm{~mm}$

Set clearance all around $=1.9 \%$ of sheet thickness

Set clearance all around $=5.4 \%$ of sheet thickness

Set clearance all around $=6.4 \%$ of sheet thickness

Set clearance all around $=3.8 \%$ of sheet thickness

Set clearance all around $=5.3 \%$ of sheet thickness

Set clearance all around $=4.0 \%$ of sheet thickness

Set clearance all around $=4.3 \%$ of sheet thickness

Set clearance all around $=3.7 \%$ of sheet thickness

Set clearance all around $=3.9 \%$ of sheet thickness

Set clearance all around $=4.2 \%$ of sheet thickness

Set clearance all around $=2.5 \%$ of sheet thickness

Set clearance all around $=2.8 \%$ of sheet thickness

Required operation $=$ piercing

Required operation $=$ blanking

Required operation $=$ notching

Required operation $=$ shaving

Required operation $=$ slotting

Required operation $=$ perforating

Required operation $=$ parting

Upper punch = piercing; and Lower punch $=$ blanking 
Table 1 continued

\begin{tabular}{|c|c|c|}
\hline no. & IF & THEN \\
\hline 24 & Required operations $=$ notching and blanking & $\begin{array}{l}\text { Upper punch }=\text { notching; and Lower } \\
\text { punch }=\text { blanking }\end{array}$ \\
\hline 25 & Required operations $=$ notching and shaving & $\begin{array}{l}\text { Upper punch }=\text { notching; and lower } \\
\text { punch }=\text { shaving }\end{array}$ \\
\hline 26 & Required operations $=$ shaving and perforating & $\begin{array}{l}\text { Upper punch }=\text { shaving; and lower } \\
\text { punch }=\text { perforating }\end{array}$ \\
\hline 27 & Required operations $=$ slotting and perforating & $\begin{array}{l}\text { Upper punch = slotting; and lower } \\
\text { punch }=\text { perforating }\end{array}$ \\
\hline 28 & Required operations $=$ slotting and parting & $\begin{array}{l}\text { Upper punch = slotting; and lower } \\
\text { punch = parting }\end{array}$ \\
\hline 29 & Required operations = nibbling and parting & $\begin{array}{l}\text { Upper punch }=\text { nibbling; and lower } \\
\text { punch }=\text { parting }\end{array}$ \\
\hline 30 & Required operations $=$ nibbling and shaving & $\begin{array}{l}\text { Upper punch = shaving; and lower } \\
\text { punch = nibbling }\end{array}$ \\
\hline 31 & Required operations $=$ parting and piercing & $\begin{array}{l}\text { Upper punch = piercing; and lower } \\
\text { punch = parting }\end{array}$ \\
\hline 32 & Required operations $=$ notching and parting & $\begin{array}{l}\text { Upper punch }=\text { notching; and lower } \\
\text { punch = parting }\end{array}$ \\
\hline 33 & Required operations $=$ perforating and blanking & $\begin{array}{l}\text { Upper punch = perforating; and } \\
\text { lower punch = blanking }\end{array}$ \\
\hline 34 & Required operations $=$ shaving and piercing & $\begin{array}{l}\text { Upper punch = piercing; and lower } \\
\text { punch }=\text { shaving }\end{array}$ \\
\hline 35 & Required operations $=$ piercing and notching & $\begin{array}{l}\text { Upper punch }=\text { piercing; and lower } \\
\text { punch }=\text { notching }\end{array}$ \\
\hline
\end{tabular}

consist of more than 300 production rules. A sample of production rules incorporated in the proposed system is given in Table 1. All production rules have been verified from a team of die design experts. As depicted in sample rules, the values of die land and die angle in a compound die depend on sheet thickness. Clearance between punch and die depends on sheet material and sheet thickness. The design features of sheet metal part decide the type of sheet metal operations to be performed on blank. For example, if design feature available on sheet metal part is oval or internal contour cut or slot, then piercing operation should be performed. The location of punch in a compound die depends on the types of required operations to be performed on sheet metal blank. For example, if perforating and blanking operations are to be performed, then die designer always prefer to locate perforating punch as upper punch and blanking punch as lower punch in compound die.

Production rules incorporated in the proposed system are coded in AutoLISP language. GUI of the system is constructed using visual basic (VB) and interfaced with AutoCAD software and AutoLISP language. A feature library is constructed for development of proposed system. On loading the module through GUI, drawing editor of AutoCAD displays feature library.

Initially, the system invites the user to enter some part details such as sheet thickness, sheet material and its shear strength through GUI. The system stores these part data automatically in a data file labeled as PD.DAT. As soon as the user enters required part detail, the system modules execute one by one and display outputs to the user. Execution of the proposed system is shown in figure 1. A brief description of each module of the system is given as follows.

\subsection{Module BLKMOD}

First activity of the process planning of sheet metal parts is blank modeling. Module labeled as BLKMOD of the proposed system has been developed for modeling of blank. The user can load the module through GUI. The drawing editor window of AutoCAD displays feature library on AutoCAD screen. User needs to select the required features from feature library and enter the size of respective feature(s). The module is able to generate part model (2-dimensional and 3-dimensional) automatically in the drawing editor of AutoCAD. The module stores its output automatically in a drawing file labeled as BLKMOD.DWG which can be used further as an input during execution of other modules.

\subsection{Module BLKNST}

The module BLKNST has been developed for nesting of blanks of sheet metal parts. Initially, module takes the input automatically from the drawing file of blank modeling labeled as BLKMOD.DWG. It also invites the user to enter 


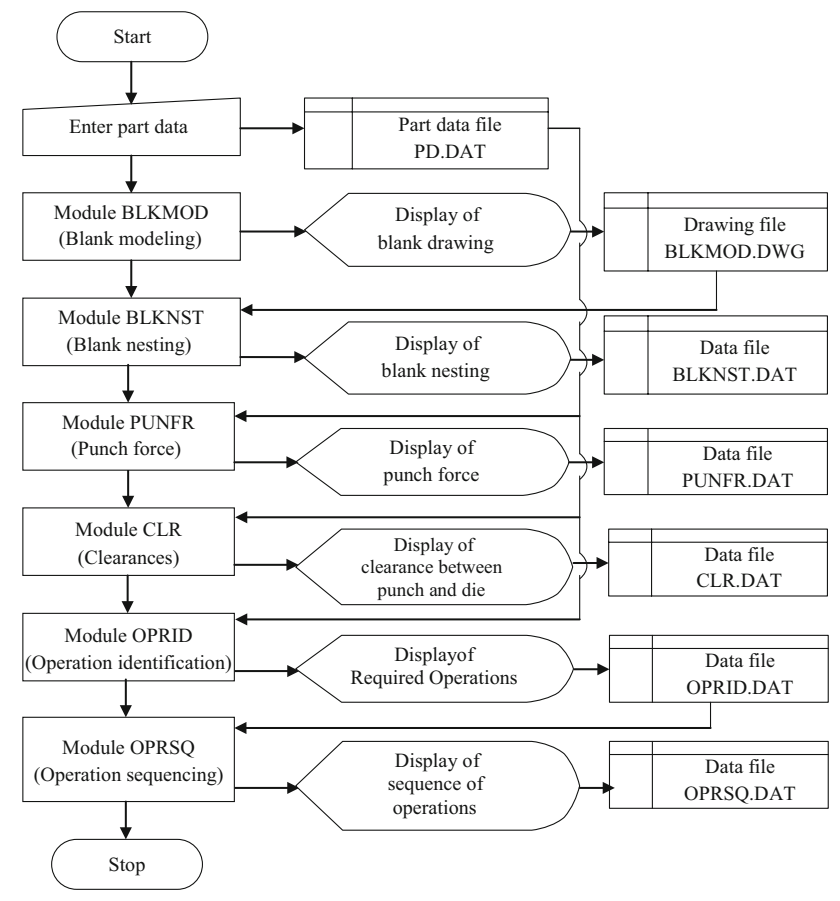

Figure 1. Execution of proposed system.

the direction of sharp edge of strip in reference to the moving direction of the strip. The outputs of this module in form of size of strip are stored in an output data file labeled as BLKNST.DAT.

\subsection{Module PUNFR}

Module PUNFR has been developed for determining punch force required to produce sheet metal part. This module takes input data automatically from part data file PD.DAT. The module stores its output in a data file labeled as PUNFR.DAT.

\subsection{Module CLR}

This module is developed for selection of proper die angle, die-land and cutting clearance between punch and die. Initially, module takes input data automatically from file PD.DAT. The expert advices imparted by the module in form of die angle, die-land and cutting clearance between punch and die are stored automatically in an output data file namely CLR.DAT.

\subsection{Module OPRID}

This module is developed for identification of sheet metal operations required for production of sheet metal parts. Initially, module takes input data automatically from file PD.DAT. Module invites the user to select the geometrical features required for manufacturing the part. Finally, the

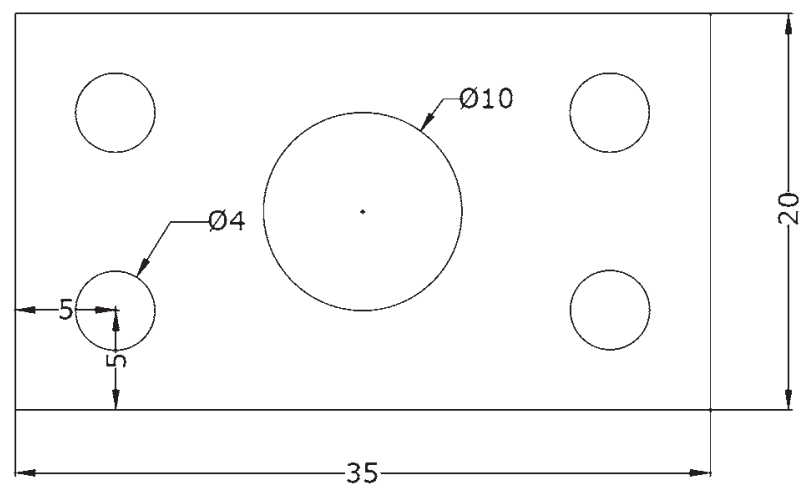

Figure 2. Example sheet metal part (all dimensions are in $\mathrm{mm}$, Sheet material $=$ Stainless Steel and Sheet thickness $=0.8 \mathrm{~mm}$ ).

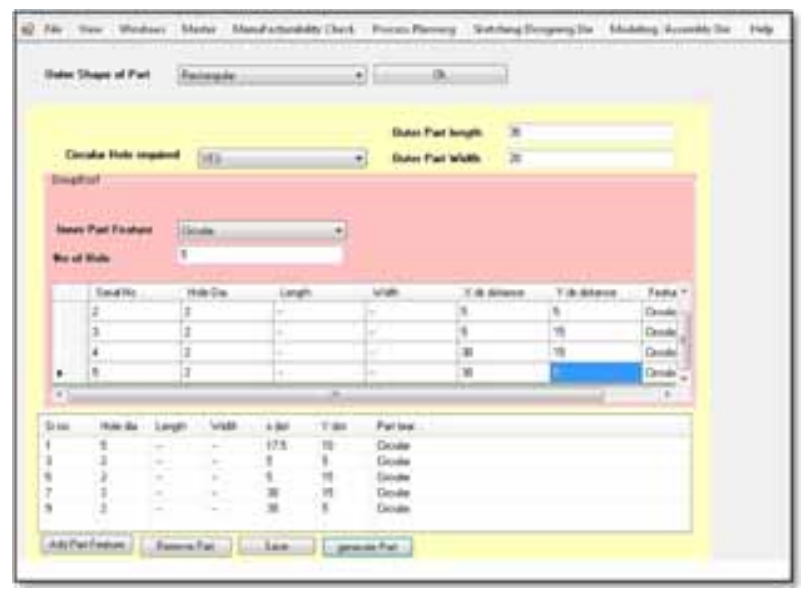

Figure 3. Input data for BLKMOD module for example part.

module imparts expert advices in the form of type of sheet metal operations required to manufacture the part. The module stores its output in a file labeled as OPRID.DAT.

\subsection{Module OPRSQ}

The module OPRSQ is developed for determination of proper sequence of operations to manufacture sheet metal part correctly and efficiently. The module is designed to take required inputs automatically from OPRID.DAT generated during execution of previous module OPRID. Finally, the module imparts expert advices in the form of operation sequence. The module stores its recommended data in a file labeled as OPRSQ.DAT.

\section{Validation of the proposed system}

The proposed expert system has been tested on wide variety of industrial sheet metal parts produced on compound die. A sample run of this system on one industrial sheet metal 


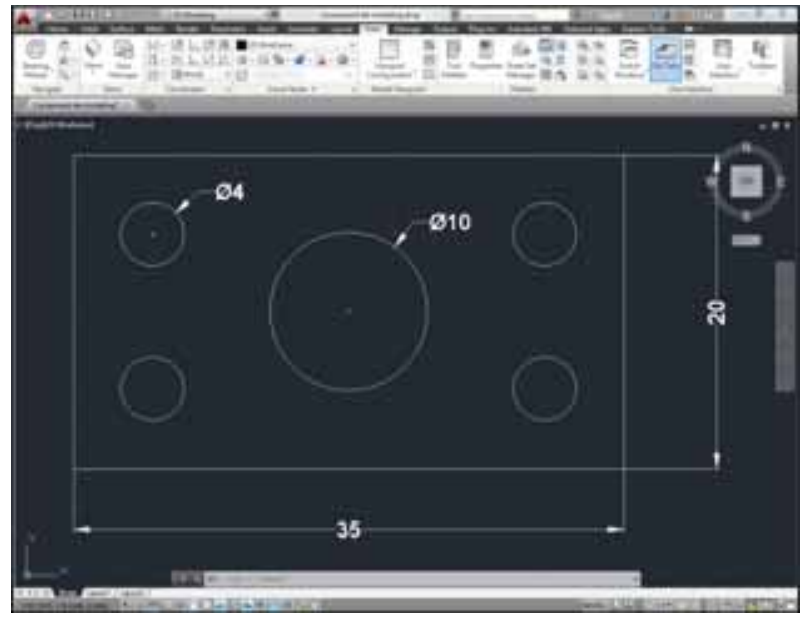

Figure 4. Output of BLKMOD module for example part.

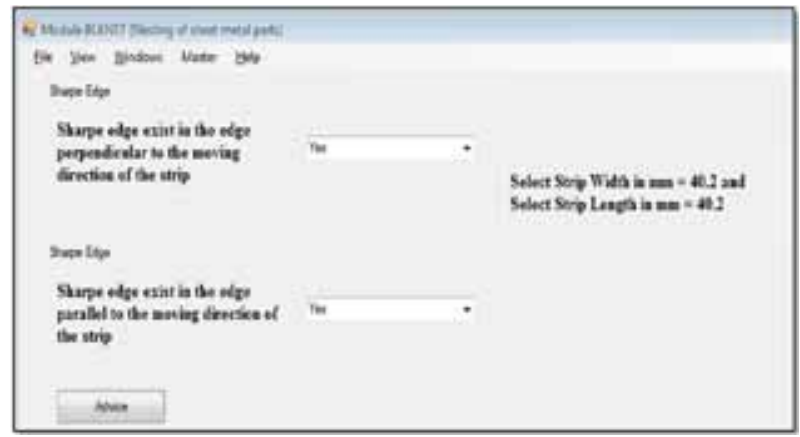

Figure 5. Output of BLKNST module for example part.

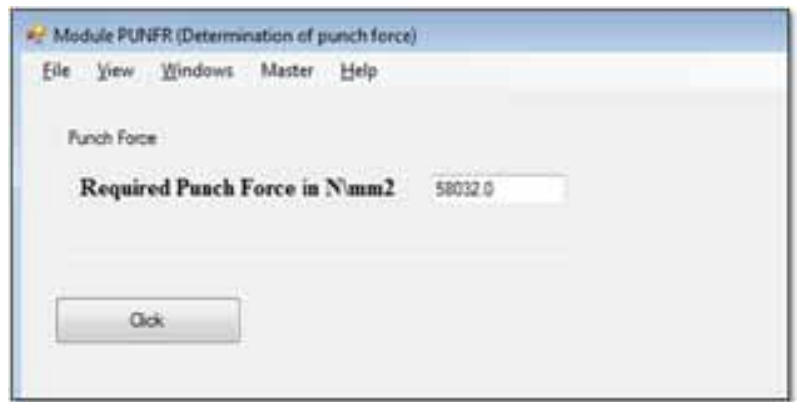

Figure 6. Output of PUNFR module for example part.

part (figure 2) of stamping industry namely $\mathrm{M} / \mathrm{s}$ Panchmahal Dies and Tools Pvt. Ltd., Vadodara, Gujarat is depicted through figures $3,4,5,6,7,8$, 9. The recommendations obtained by the system modules for process planning of sheet metal parts were found to be reasonable and very similar to those actually used in the industry for the example part. Different modules of the proposed system render enough advices and provide sufficient design data for process planning of sheet metal parts produced on compound die.

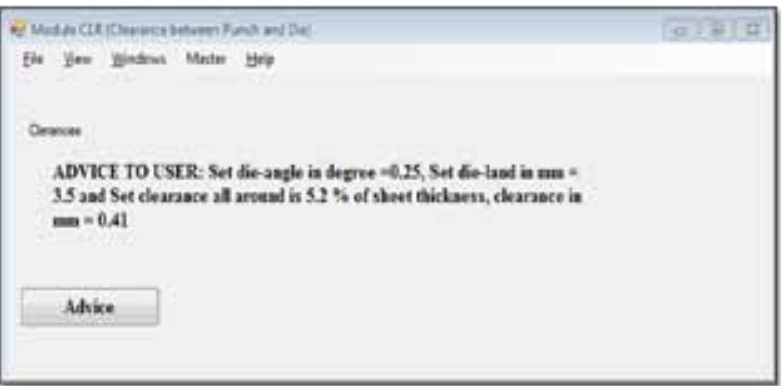

Figure 7. Output of CLR module for example part.

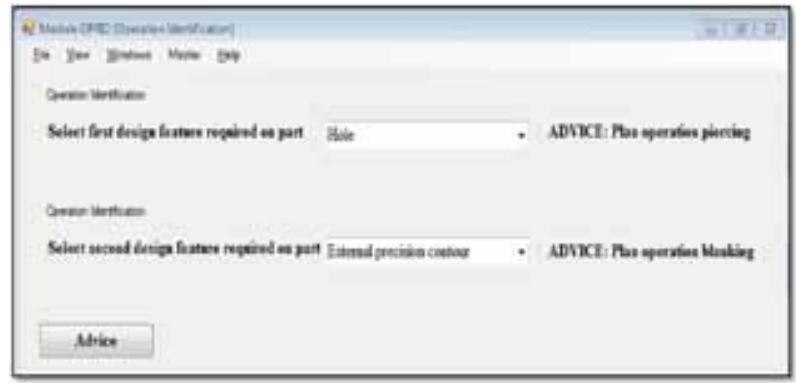

Figure 8. Output of OPRID module for example part.

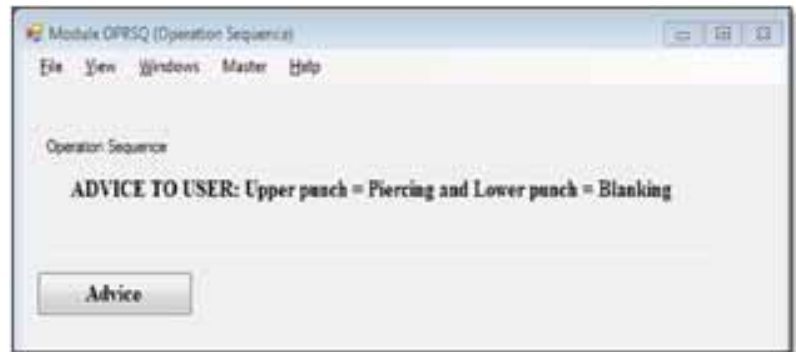

Figure 9. Output of OPRSQ module for example part.

\section{Conclusions}

In this paper, research work involved in the development of an expert system for process planning of sheet metal parts produced on compound die is described. The proposed system has been developed using production rule-based expert system approach of artificial intelligence. The developed system is capable to assist process planers and die designers of stamping industries for modeling of blank of sheet metal part, nesting of blank, determining punch force required on sheet metal parts, selection of clearance between punch and die, identifying the sheet metal operations for manufacturing the part and determining the proper sequence of operations. The developed system has been tested successfully in various sheet metal industries. The system is capable of accomplishing the tedious and timeconsuming task of process planning of sheet metal parts in a very short time period. All modules of proposed system are integrated. The system is user friendly therefore even a 
semi-skilled designer can perform the task of process planning of sheet metal parts easily using the proposed system. The low cost implementation of the proposed system makes it affordable even for small scale stamping industries.

In future, research efforts are required to develop an expert system for selection of size of die components and an automatic die modeling system to model major die components of compound die and die assembly. The output data files generated during execution of the proposed system PPCD can be recalled automatically for development of these systems.

\section{Acknowledgments}

Authors thank all domain experts for providing expertise in the development of proposed expert system. Authors also acknowledge the sanction of the project on "Automation of design of compound dies for sheet metal industries" (File No. SB/S3/MMER/0061/2013) by the Science \& Engineering Research Board (SERB), Department of Science and Technology (DST), Government of India, New Delhi.

\section{References}

[1] Naranje V and Kumar S 2010 AI applications to metal stamping die design - A review. World Acad. Sci. Eng. Technol. 44: 1526-1532

[2] Kumar S and Singh R 2004 A low cost knowledge base system framework for progressive die design. J. Mater. Process. Technol. 153-154: 958-964

[3] Xiao X, Chen S, Wang G and Xiao J 1990 An expert system for process planning for drawing. Adv. Tech. Plast. 1: 545-549

[4] Hoffmann M, Geifiler U and Geiger M 1992 Computer-aided generation of bending sequences for die-bending machines. J. Mater. Process. Technol. 30: 1-12
[5] Fang X D and Tolouei-Rad M 1994 Rule-based deep-drawing process planning for complex circular shells. Eng. Appl. Artif. Intell. 7: 395-405

[6] Jin Z, Luo S and Daniel Fang X 2001 KBS-aided design of tube bending processes. Eng. Appl. Artif. Intell. 14: 599-606

[7] Kang S S and Park D H 2002 Application of computer-aided process planning system for non-axisymmetric deep drawing Products. J. Mater. Process. Technol. 124: 36-48

[8] Shi X, Chen J, Peng Y and Ruan X 2002 Development of a knowledge-based process planning system for an auto panel. Int. J. Adv. Manuf. Technol. 19: 898-904

[9] Hussein H M A and Kumar S 2008 A computerized retrieval system for sheet metal parts. Asian Int. J. Sci. Technol. Prod. Manuf. 1: 31-40

[10] Tsai Y L, You C F, Lin J Y and Liu K Y 2010 Knowledgebased engineering for process planning and die design for automotive panels. Comput.-Aided Des. Appl. 7: 75-87

[11] Potocnik D, Pesan B, Balic J and Ulbin M 2011 Intelligent system for the automatic calculation of stamping parameters. Adv. Prod. Eng. Manag. 6: 129-137

[12] Potocnik D, Ulbin M and Dolsak B 2012 Knowledge based system for supporting the design of a plate-press. J. Comput. Inf. Sci. Eng. 12: 1-5

[13] Naranje V and Kumar S 2013 A knowledge-based system for strip-layout design for progressive deep drawing dies. Int. J. Comput. Appl. Technol. 48: 222-234

[14] Boljanovic V and Paquin J R 2006 Die design fundamental. Industrial Press Inc, New York

[15] Jones F D 1944 Die design and die making practice. The Industrial Press, New York

[16] Kumar S 2006 A contribution to the development of knowledge based system for intelligent design of progressive dies. $\mathrm{PhD}$ thesis, Maharshi Dyanand University, Rohtak, India

[17] Smith D A 1990 Die design handbook. 3rd edn SME, New York.

[18] Suchy I 2006 Handbook of die design. The McGraw-Hill Companies, New York 